\title{
Influence Of Smartphone Attributes On Student's Buying Decision In Lagos State Tetiary Institutions
}

\author{
Patrick Kunle A Ladipo ${ }^{1}$, Mufutau Akanbi Awoniyi ${ }^{2}$, Olushola Solomon Akeke ${ }^{{ }^{*}}$ \\ ${ }^{1}$ Department of Business Administration, University of Lagos, Akoka, Lagos, Nigeria \\ ${ }^{2}$ Department of Marketing, , Lagos State University, Ojo, Nigeria \\ *solomonyz4real@yahoo.com
}

\begin{abstract}
The study was carried out to evaluate the influence of smartphone attributes on student's buying decision in Lagos State Tertiary Institutions. Research design adopted was purely descriptive, employing cross sectional survey method in data collection. Data for the study were generated through the use of structured questionnaire and administered to a sample of 362 out of 3,792 students in selected tertiary institutions in Lagos State. Data collected were analyzed using Multiple Regression Analysis. The results showed that all smartphone attributes considered in the study were found to be positively and significantly related to student's buying decision. Specifically, technology attribute has highest impact on student's buying decisions, followed by application and price attributes. The study concluded that technology, application and price are considered the most top three attributes that significantly influenced student's buying decision of Smartphone. It was recommended that firms should focus on improving their technology in other to bring about innovative features and application, and more importantly adopt variety of price strategies while not neglecting the image and design attributes, as these were regarded as secondary attributes in determining consumers' choice of Smartphone.
\end{abstract}

Keywords: Buying Decision, Smartphone Attributes

https://doi.org/10.26905/jmdk.v6i1.1938

\section{INTRODUCTION}

The survival and growth of organizations today depends on the extent to which it is able to provide products and services that satisfy its numerous customers. Customers will feel satisfied with products that possess the requirements that lead to informed decision to make purchases one hand and if they are able to perform to expectations. On the other hand, this of course, the reason why Malasi (2012) argued that products and brand attributes are significantly important to consumers when making their purchasing decision. Thus, the upsurge in the availability of smartphone in developing economies has greatly revolutionized the thinking and life-style of students in tertiary institutions. Since the emergence of smartphone in Nigeria in the late 1990's, same has been found to have positively impacted the social, academic and economic life's of students in higher institutions and by extension increasing their knowledge globally and commitment to a serious academic pursuit based on smartphone attributes. (Mojaye, 2015).

The various and innumerable benefits of smartphones have accordingly made the product virtually indispensable amongst students resulting in technological 
orientation with attendants improved life style. (Lau, Lam \& Cheung, 2016 \& Mohan, 2014). Hence, Tan, Yeh, Chen, Lin and Kuo (2015) maintained in their studies that smartphone attributes will include the following important features: Price related features, technology related features, design related features, application related features and image related features. Malasi (2014) further posited that firms work towards satisfying and meeting consumer's need through its various products attributes/features. More so, Lay-Yee, KokSiew and Yin-Fah (2013), confirms that smartphone features are merely more than just making phone calls and text messages, but its ability to have high speed internet accessibility, digital media and multimedia features such as videos, chatting, music and picture. More so, to be able to make use of small computer programs like installation Apps, etc. It is therefore very important for firms/marketers to anticipate, discover and identify the influential factors to deal with changing customer needs, taste and preference and the intense competition in the smartphone market. (Khan \& Rohi, 2013).

Despite the pervasiveness of smartphone penetration in Nigeria, studies are very few and inadequate for understanding of smartphone attributes that influences buying decisions and most especially among students in Nigeria. This study is therefore intended to understand the influence of smartphone attributes on student's buying decision. Although, many researches and studies have been preliminarily carried out on factors that affect consumer choice of mobile phones. (Yeh, Chen, Lin \& Kuo, 2015; Mokhlis \& Yaakop, 2012; Sata, 2013; Malasi, 2012; Oghojafor, Ladipo \& Rahim, 2012). However, these studies have not duly captured recent development in modern technology.

Thus, smartphone is importantly viewed as indispensable product whose performance function are judged based on such attributes such as technology, price, design, image and application. (Lau, Lam \&
Cheung, 2016; Mohan, 2014 \& Tan, Yeh, Chen, Lin \& Kuo (2015).

The broad objective the study seeks to achieve is to evaluate the influence of smartphone attributes on student's buying decision in Lagos State Tertiary Institutions. However, the following under listed are the specific objectives of the study: 1) to determine the influence of price related attributes on student's buying decisions of Smartphones, 2) to investigate the influence of technology related attributes on student's buying decisions of Smartphones, 3) to examine the influence of design related attributes on student's buying decisions of Smartphones, 4) to identify the influence of application related attributes on student's buying decisions of Smartphones, 5) to determine the influence of image related attributes on student's buying decisions of Smartphones.

\section{Literature Review}

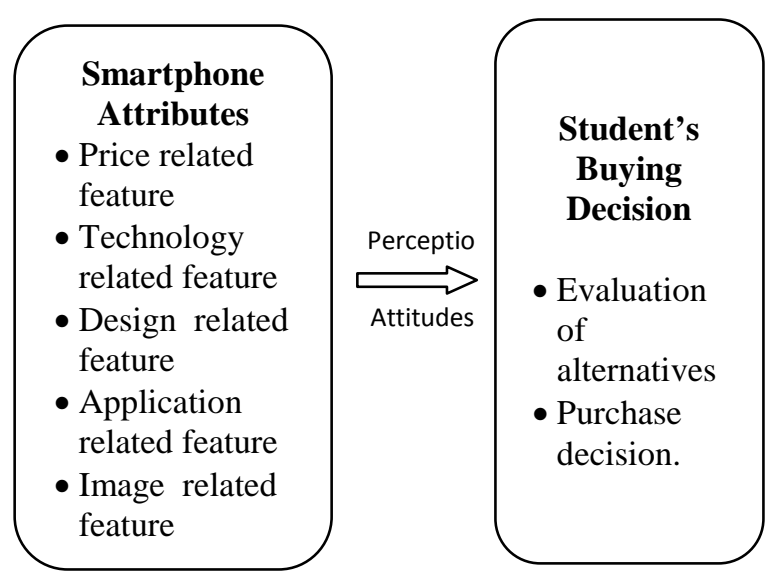

Figure 1. Conceptual model of the study Source: Modified from (Kotler \& Armstrong, 2012).

Why do we buy things?, how do we decide to buy what we already bought ?, how do we know where and when to buy these products ?. These are questions we do often ask ourselves. Hence, marketing professionals are curious to knowing the answers to these resounding questions. It is because, if they can get answers to these questions, then they will have better chance 
of creating and communicating products to potential buyers.

However, the decision consumer makes while buying product is the focal point marketers try to understudy, because consumers make different types of decisions in everyday life. And in other to withstand the competitive environment, it is important for firms to exercise much effort on researching consumer buying behavior and obtain detailed information on what consumers' purchase, where they purchase, when they make their purchases and why they purchase. (Sabnam, 2016).

A buyer will usually pass through five different stages of problem recognition, information search, evaluation of alternatives, purchase decision and post purchase decision in other to reach his/her buying decision. That is, evaluate his/her needs, choose the best one according to his/her need and available resources and purchase it. But for the purpose of this study, it is assumed that students have passed through the first and second stage of the decision process by recognizing the need for using a smartphone, and are also well informed about this product. Hence, the students is left with the third and fourth stage of the decision process by evaluating the smartphone attributes based on their perception and attitudes towards the product, and thereafter make purchases.

This therefore encourages marketers in the smartphone industry to rather focus on the evaluation of alternatives, and purchase decision.

\section{Smartphone Attributes}

Buyers do not acquire products for the sake of the products, but for the utility/satisfaction provided by characteristics and functionality of the product's attributes. (Lancaster, 1966, Zhang, Rau \& Zhou, 2015). However, many of the product characteristics that are important from the point of view of consumers as well as designers are neither physical nor objective.
In today's competitive market, the marketers are looking towards building a long term profitable business relationships with the customer. Because consumers use product attributes to evaluate a product in relation to the benefits they seek before intending to purchase the product. Oghojafor, Ladipo \& Rahim, 2012). (Shaharudin, Hassan, Mansor, Elias, Harun and Aziz (2010) also reported According to Kotler and Armstrong (2012) that marketing has gone through series and stages of marketing evolution. That is, from the production concept to marketing and societal concept. In marketing concept, the achievement of the overall organization goals depends on the extent of its customer satisfaction and how best the company delivers satisfactions better than its competing counterparts. From the marketing point of view, competitive advantage can be achieved through a series of intermediate objectives such as offering a distinctive product attributes. Furthermore, to increase the brand loyal customer base, it is suggested that an organization needs to create awareness and communicate the benefits of these attributes.

Smartphone is an electronic device that provides varieties of functions and usage with ease. Smartphone is a mobile device which is more than merely making and receiving phone calls, text messages, and voice mail. The basic feature of a Smartphone is the ability to have access to the internet and also to be able to access digital media such as picture, music and videos. Also, Smartphone needs to have the ability to make use of small computer programs called applications or apps (Karen, Han \& Benjamin, 2013).

Attributes on the other hand, according to Oghojafor, Ladipo and Rahim (2012) in Peter and Olsen (1994) and Aaker, Batra and Myers (1992) categorized attributes into concrete attributes and abstract attributes. A concrete attributes can be referred to as physical attributes because of its objective and tangible characteristics which can be assessed by using criteria such as colour and 
shape. While an abstract attributes is subjective and intangible, they cannot be easily measured and come inform of the product design, technology and operating system.

Thus, smartphone attributes will include features such as application, high gigabytes of storage, large screen and powerful processor. However, attributes can also come inform of touch screen, camera resolution functionality, $\mathrm{WiFi}$, high resolution display, e.t.c.

Romariuk and Sharp (2003) thereby, suggested that firms should focus more on how many attributes/features the smartphone should be associated with. Which Tan, et al. (2015) maintained that smartphone attributes will include the following important features: Price, technology, design, application and image related attributes.

\section{Price Related Attributes}

Park, Wiriady, Surya and Putri (2014) quoting Mokhlis and Yaakop (2012) that "Price has been noted to being a critical factor influencing student's buying decisions of smartphones product”. Dziwornu (2013) further revealed that the buying decision of students purchasing mobile phone was mostly affected by price, as they are likely to associate the price charged in relation with the product quality. However in similar vein, studies have shown how prices affect smartphone purchases. (Sata, 2013; Park, Wiriady, Surya \& Putri, 2014 \& Mokhlis \& yaakop, 2012). Malasi (2012) asserted that consumers will gladly buy products that have lower prices. Therefore, it can be rightly assumed that there is relationship between price and student's decisions of smartphones, particularly when affordability is considered

According to Tan et al. (2015) Investigated that price is influenced by fashion and values which in turn affects the smartphone Apps uni-directionally. Hence, customers do not view price in isolation when assessing whether the Smartphone is worth its value. Price is the odd-one of the elements in marketing mix, because it is the revenue generator. (Jobber, 2004). The price of a product is what the company gets back in return for all the effort that is put into production and marketing of the product. Therefore, we can rightly say that price is an important attributes that enhances product quality when other attributes available are limited. (Dodds \& Monroe, 1985). Jacoby and Olson (1977) also dichotomized price into two: - Objective price (the actual price that is placed on a product) and perceived price (this is an encoded and assumed price of the consumer). Price no doubt influences evaluation and purchase decision.

\section{Technology Related Attributes}

Technology Has Revolutionalized The Way and how we communicate with ourselves and even with ease. Seiler and beall (2005) states that technology has advanced so quickly. Digital cameras allow them to understand and share pictures of with others, members of the family and special events with friends all over the world. Technology plays an important and powerful role in human lives. It has an impact on society communication style/system, the interactions, the cross fertilization of ideas, learning and listening. However, studies have shown how technology attributes influences students buying decisions of evaluation and purchases. (Sata, 2013; Park, Wiriady, Surya \& Putri, 2014 \& Mokhlis \& yaakop, 2012). Thus, it is the operating system (OS), availability of near field communication (NFC), data transmission method such as bluetooth, phone speed, ROM and storage capacity. In view of this, technology no doubt influences student's evaluation and purchase decisions.

\section{Design Related Attributes}

Another way to add customer value is through product design and style. Some of the previous studies have mentioned that physical appearances of the mobile phones, including size, color, design, weight, and keyboard have major impacts on final purchase decision for mobile phone. (Sata, 2013; Tan, Yeh, Chen, Lin \& Kuo, 2015 \& 
Mokhlis \& yaakop, 2012). Research conducted by Yang, He, and Lee (2007) found out that Chinese counterparts intend more to impress themselves and others with their mobile phones' fancy design and appearance.

Companies however develop reputations for outstanding style and design. Kotler et al (2002) asserted that design is a wilder and broader concept than style and that style simply describes the appearance of a product. Because, design will offer one of the most potent tools for differentiating and repositioning product of all kinds. Therefore, good design in Smartphone will create and attract attention, improve product performance, cut production costs and give the product a strong competitive advantage in higher institutions and most especially in Lagos state. Smartphone attributes come inform of application, high gigabytes of storage, large screen (width and touch screen) and powerful processor, touch screen, camera resolution functionality, Wi$\mathrm{Fi}$, high resolution display. Attributes such as body design (shape, weight and dimension) can also define a design related attributes. In view of this, design no doubt influences student's evaluation and purchase decisions.

\section{Application Related Attributes}

Smartphones run on operating system (OS) that allows the installations of third party and vendor applications or "Apps". Most Smartphone OS' have their own dedicated Apps that are normally available from a portal for downloading, frequently referred to as an "App Store”. (Uys, Mia, Jansen, Van der schyff, Josias, Khusu, Gierdien, Leukes, Faltein, Gihwala, Theunissen \& Samsodien, 2012). Karen, Han and Benjamin (2013) reported that Smartphone make use of small computer programs called applications or Apps.

Smartphone Apps range from various apps like e-wallet, games, e-transact, Google stores, e-Book Readers, Navigation Software, Services providing news and weather feeds, to Apps allowing users to access internet services such as email,
Wikipedia, YouTube, Face book and other social networking Apps. In view of this, application no doubt influences student's evaluation and purchase decisions.

\section{Image Related Features}

This is the brand, brand name, fashion or trendy to use. Brand name is another factor that influences students' evaluation and buying decision in the mobile phone markets. Research conducted by Karjaluoto, Karvonen, Kesti, Koivumak, Pakola, Ristok and Salo (2005) found out that brand is one of the most influential factors that affect the purchase of mobile phone. In addition, they also found out that students rarely change their mobile phone brand due to the fact that it is much easier to stay with the same brand with familiar-user interface and menus. Thus, it is hypothesized that image affect consumers' evaluation and purchase decision.

Although firms provide the impetus to brand creation through marketing programs and other activities, ultimately a brand resides and is positioned in the minds of consumer. Kotler and Keller (2012) defines it as a name, term, sign , symbol, or design, or combination of them, which is used to identify the product offering of a seller and to differentiate them from those of competitors. Brand name being a compact form of communication may connotes meanings such as brand image that consumers may consider critical in the choice of Smartphone.

Corporate name: When a company name is less well known and means little to consumers, it is likely that it would influence negative purchase intention since consumers may most likely have mixed perception of the company's products. (Idoko, Ireneus, Nkamnebe \& Okoye, 2013, \& Nelson, 2002).

Product quality: This is an essential component to consider when attemptingto create an image for a brand and enhancing customer satisfaction, increasing customer satisfaction. (Lonial \& Selimzaim, 2015).

Shaharudin et al. (2011) carried out a study on the relationship between product quality 
and purchase intention and identified that product quality is based on eight quality dimensions which includes: Performance, features, conformance, reliability, durability, serviceability, aesthetics, and Customer perceived quality. Studies have rightly shown that image attributes plays a major role in influences students buying decisions of smartphone. (Sata, 2013; Tan, Yeh, Chen, Lin \& Kuo, 2015 \& Mokhlis \& yaakop, 2012).

\section{Multi-Attributes Attitude Model}

Fishbein's multi-attribute attitude model was mainly developed by Martin A. Fishbein in 1963, in which he stated that the attitude towards certain products will be reflected by the evaluation of important attributes, and then attitude can be assessed by measuring the evaluation of these attributes.

According to this model, attitudes are viewed as having two basic components, one is belief about the specific factors of an object and another is the overall evaluation about the specific factors of an object. It implies how an individual evaluates the importance of each attributes of the object in satisfying his/her needs.

This is formulated as follows:

Ao $=\sum_{i=1}^{n} b i . e i$

Where

$\mathrm{A}_{\mathrm{o}}=$ person's overall attitude towards the object or product.

bi = the strength of one's belief about the attribute (i) or factor of that object /product.

ei $=$ the performance rating of product attribute (i).

$\mathrm{n}=$ number of important/salient product attribute.

This model helps to identify product strengths and weaknesses from customer's perspective and it also helps to determine if customers perceive the product as intended.

\section{Stimulus - Response Model Of Buyer Behavior}

Marketers need to understand the buying decisions of its consumers. Because, consumers make buying decisions every day and the main focal point of marketer's effort is to know the buying decisions of consumers. (Kotler \& Armstrong, 2012). Kotler, Armstrong, Saunders and Wong (2002) further stated that firms will use more of their resources than ever to study consumer's buying behavior. That is, looking for answer to question such as, "how do consumers respond to various marketing stimuli that the company might use"? However, knowing the answer to this question will create a great competitive advantage over its competitors.

Thus, firm utilizes various marketing efforts to influence the decision of consumers. The marketing stimuli, interprets the firms product offering, pricing, promotional effort and placing the product. Marketers use these stimuli to persuade consumers to buy smartphone. And the other stimulus, explains the economic, technological, political and the psychological factor that are likely to affect and influence the consumer when considering to buy smartphone. These stimuli presented before consumers by firms are however dealt with by the buyer's black box, which comprises the buyer's characteristics and the buyer's decision process. The marketers know nothing about the black box as it is a metaphor used for consumer's mind but firms can only predict what goes on inside the black box. After the buyer receives the stimuli and processes it, then consumers come up with an observable response of product choice, brand choice, purchase timing, purchase amount and purchase frequency. (Sabnam, 2016).

\section{Empirical Review}

Romariuk and Sharp (2003) suggested in their studies that firms should focus more on how many attributes the smartphone should be associated with. Whilst of course, 
Oghojafor, Ladipo and Rahim (2012) maintained in their study that attributes play vital role in the consumer decision making process since consumers evaluate and compare competitive product based on attributes, and that marketers use product attributes to differentiate between competing product. Besides from trends to develop a positioning strategy based on unique and relevant attributes. The study further informs that design has the most important attribute. In view of this, Zhang, Rau and Zhou (2010) conceived that consumer perception and understanding of mobile phone product attributes are influenced by the following factors: common functions, appearance, multimedia functions, connectivity, personal information management functions, body design, brand \& country, and product image. These factors can be used as basis for understanding product attributes and its influencing potentials/power.

A comparative study of Tan, Yeh, Chen, Lin and Kuo (2015) examined and maintained that product attributes will include the following important dimensions: Price, technology, design, application and image related features. However, studies have proven that innovative product features and price are the most valued factors consumers take into consideration in their choice of Smartphone. (Mokhlis and Yaakop, 2012 \& Sata, 2013).

According to Park, Wiriady, Surya and Putri (2014). They proposed that the multidimensional factors impacting the consumer choices of mobile phones have been investigated and analyzed through a plenty of studies over time and across the nations. On the other hands, Karjaluoto et al. (2005) reported that price, brand, interface, and properties tend to be influential factors affecting the actual choice amongst mobile phone brands. Also, Ling, Hwang and Salvendy (2006) investigated college students to identify their preference of current mobile phone. The results of their survey indicated that the physical appearance, size and menu organization of the mobile phones are the most determinant factors affecting the choice of mobile phones.

Das (2012) conducted an empirical research based on survey method on factors influencing buying behavior of youth consumers towards mobile handsets in India. According to the study, a handset of reputed brand name, smart appearance, and with advanced value added features, pleasurability and usability; is the choice of young consumers.

Han et al. (2004) later carried out a user study on 65 design features of 50 different mobile phones. They developed regression models to link the design features to overall satisfaction and 'luxuriousness', 'attractiveness' and 'harmoniousness'. They found that a number of design features plays main role for enhancing satisfaction, such as phone size and weight, color, material, button shape and interface features.

More so, study conducted by Singh and Goyal (2009) found out that physical appearance, brand, value added features, and core technical features are more important than price to youngsters.

Ultimately, by exploring and reviewing various researches on smartphone attributes impacting students' decision of Smartphone, it is clear that these studies only show how smartphone affects student's choices. However, studies are limited on the ultimate smartphone attributes influencing student's evaluation and buying decisions in tertiary institutions, Lagos, Nigeria.

\section{Research Hypotheses}

The study aim is to ascertain the influence of smartphone attributes on buying decisions among students in tertiary institutions. The specific objectives are therefore set to evaluate the following alternative hypotheses $(\mathrm{H})$ :

$\mathbf{H}_{1}$ : There is a significant affect between price related attribute and student's buying decision of Smartphone.

$\mathbf{H}_{2}$ : There is a significant affect between technology related attribute and student's buying decision of Smartphone. 
$\mathbf{H}_{3}$ : Design related attribute will significantly affect students' buying decision of Smartphone.

$\mathbf{H}_{4}$ : There is a significant affect between application related attribute and student's buying decision of Smartphone.

$\mathbf{H}_{5}$ : Image related attribute will significantly affect student's buying decision of Smartphone.

\section{METHOD}

The research design was based on descriptive research design, employing cross sectional survey method in data collection.

\section{Population and Sample}

The population of the study comprise of the following figure: University of Lagos with 3000 students and Federal College of Education (Tech.), Akoka with 792 students. Therefore, our total population (N) is 3,792 students. The study will be using a multistage sampling method. At the first stage, the faculty of business administration of the University of Lagos is considered, and the school of business education of the federal college of education, Akoka is also used. At the second stage, Yamane model was adopted to determine the sample size for this study.

$$
\begin{aligned}
& \mathrm{n}=\mathrm{N} \\
& 1+\mathrm{N}(\mathrm{e})^{2} \\
& \text { Where: } \mathrm{n}=\text { Sample size } \\
& \mathrm{N}=\text { Total population } \\
& \mathrm{e}=\text { Sampling error }
\end{aligned}
$$

However, stratified sampling method which is a tool of probability sampling technique was used to select a total of 362 students and according to the Yamane formula.

Thus, a total number of three hundred and sixty-two (362) copies of questionnaire were administered to respondents, using multi-stage and random sampling methods.

\section{Study Instrument}

The data collection instrument was purely a structured questionnaire in the direction of multiple choice questionnaire type. It was subjected to test of reliability and validity. The validity was achieved by subjecting the instrument to a review across doctoral students and lecturers in University of Lagos. Whose contribution assisted in generating the final draft.

The reliability test was carried out through the instrument of cronbach alpha test , which yielded positive results of 7.28. See Appendix A.Data analysis were carried out using descriptive and inferential statistics and more importantly multiple regression.

\section{RESULTS AND DISCUSSION Result}

The result of the analysis revealed that the majority of respondent that partook in the survey was female students with 53.8 percent. And more so, the findings revealed that majority of this respondent are between the age brackets of $16-28$ with 61.4 percent. The regression model adopted for this study is as follows:

Regression Model/Equation

$\mathrm{SBD}=\beta_{0}+\beta_{1} \mathrm{I}+\beta_{2} \mathrm{~A}+\beta_{3} \mathrm{D}+\beta_{4} \mathrm{P}+\beta_{5} \mathrm{TRA}$ Therefore, if $Y=\beta_{0}+\beta_{1} \ldots$

Then, SBD= $3.051+0.022(\mathrm{I})+0.445(\mathrm{~A})+0.131(\mathrm{D})+0.348(\mathrm{P}$ ) +0.753 (TRA)

Where :

SBD = Students buying decision

$\mathrm{I}=$ Image

A = Application

$\mathrm{D}=$ Design .

$\mathrm{P} \quad=$ Price

TRA = Technology Related Attributes

$\mathrm{B}=$ This is the regression coefficient which is computed by the regression tool.

$\beta_{0} \quad=$ This is the regression intercept.

\section{Re-statement of Alternative Hypotheses:}

$\mathbf{H}_{1}$ : There is a significant affect between price related attribute and student's buying decision of Smartphone.

$\mathbf{H}_{2}$ : There is a significant affect between technology related attribute and 
student's buying decision of Smartphone.

$\mathbf{H}_{3}$ : Design related attribute will significantly affect students' buying decision of Smartphone.

$\mathbf{H}_{4}$ : There is a significant affect between application related attribute and student's buying decision of Smartphone.

$\mathbf{H}_{5}$ : Image related attribute will significantly affect student's buying decision of Smartphone.

\section{Regression Analysis}

The result shows the multiple correlation coefficient ' $R$ ' $(0.986)$ which is the correlation between the variables, while $\mathrm{R}$ square (0.972) indicates the amount of variance in the choice of smartphones by the attributes. In this case, smartphone attributes account for $97.2 \%$ of the variance in consumer choices of smartphones. And that the $\mathrm{P}$ (Sig.) $0.000<0.05$ shows that a positive relationship existed between the students buying decision and smartphone attributes. Hence, the alternative hypotheses previously stated above are hereby accepted. Based on ANOVA, the cumulative p-values of the regression results shows that $\mathrm{p}$ (sig) $000.0<0.005$ and this affirm that the model significantly predicts student's buying decision of smartphone.

Table 1. Coefficients

\begin{tabular}{|c|c|c|c|c|c|}
\hline \multirow[t]{2}{*}{ Model } & \multicolumn{2}{|c|}{$\begin{array}{l}\text { Unstandardized } \\
\text { Coefficients }\end{array}$} & \multirow{2}{*}{$\begin{array}{c}\text { Standardized } \\
\text { Coefficients } \\
\text { Beta } \\
\end{array}$} & \multirow[t]{2}{*}{$\mathbf{t}$} & \multirow[t]{2}{*}{ Sig. } \\
\hline & B & Std. Error & & & \\
\hline Constant & 3.051 & .238 & & 12.796 & .000 \\
\hline Price & .348 & .037 & .012 & 11.201 & .001 \\
\hline Technology & .753 & .046 & .232 & 9.736 & .000 \\
\hline Design & .131 & .036 & .050 & 5.867 & .046 \\
\hline Application & .445 & .042 & .063 & 8.066 & .007 \\
\hline Image & .022 & .035 & .035 & .636 & .125 \\
\hline \multicolumn{6}{|c|}{ a. Dependent Variable: students buying decision of smartphone } \\
\hline
\end{tabular}

Source: Authors' computation

The regression results in Table 1 shows that three out of five product attributes will contribute significantly to student's buying decision of smartphone. Therefore, it is evident from this result that technology: $ß=0.753 ; \quad t(327)=9.736, \quad$ application: $\quad \beta=$ $0.445 ; \mathrm{t}(327)=8.066$ and price: $\beta=0.348$; $\mathrm{t}(327)=11.201$. However, design: $\beta=0.131$; $\mathrm{t}(327)=5.867$ and image: $\beta=0.022 ; \mathrm{t}(327)=$ 0.636 was not significant as $\mathrm{P}>0.05$.

\section{Discussion}

With regards to hypothesis one, that there is a significant relationship between price related attribute and student's buying decision of Smartphone. Thus, the ( $(=0.348)$ further confirms that smartphone attribute of (Price) positively influence student's buying decision of smartphone and therefore implies that an increase in price will result into $34.8 \%$ increases in student's buying decision. This however corroborates the studies of Mokhlis and Yaakop (2012) and Sata (2013) that innovative product features and price are the most valued factors consumers take into consideration in their choice of Smartphones.

By validating hypothesis two, Technology related attributes positively influence student's buying decisions of smartphone with a $(§=0.753)$, this implies that an increase in technology will cause $75.3 \%$ increase in student's buying decision of smartphone. Thus, a comparative study of Tan et al. (2015) examined and maintained that consumers will assess product features of smartphones on the basis of its technological advancement. Hence, studies have proven that innovative product features and price are the most valued factors consumers take into consideration in their choice of Smartphone. (Mokhlis \& Yaakop, 2012 \& Sata, 2013).

The ( $ß=0.131)$ shows that design positively influence student's buying decision of smartphone and therefore hypothesis three falls within the accept region, which also implies that an increase in design attribute will cause a $13.1 \%$ increase in student's buying decision of smartphone. This result is in line with the studies of Han et al. (2004) that a number of design features plays main role for enhancing satisfaction, such as phone size and weight, color, material, button shape and interface features. 
Application shows a positive influence on student's buying decision of smartphone with a $(\S=0.445)$, this implies that an increase in application will result into $44.5 \%$ increases in student's buying decision of smartphone.

Image Attributes positively influence student's buying decision of smartphone with a $(\Omega=0.022)$, which makes hypothesis five to be accepted. This also implies that an increase in image will result into $02.2 \%$ increase in student's buying decision of smartphone. This also corroborates with the study of Ling, Hwang and Salvendy (2006) which investigated college students to identify their preference of current mobile phones. The results of their survey indicated that the physical appearance, such as image, size and menu of the mobile phones are the most determinant factors affecting the choice of mobile phones.

However, the result showed that all smartphone attributes considered in this study will positively and significantly influence students buying decision of smartphone. Specifically, technology attribute has high impact on students buying decision of smartphone, followed by application and price attributes. The study concluded that technology, application and price are considered the most top three attributes that significantly influence students buying decision of smartphone.

\section{Conclusion}

Given the analogy in previous sections of this study, we can rightly say that marketing is fundamental importance to business organizations. Hence, there is need for us to study this function of business activity in details. And interestingly, the essence of marketing is to meet unmet needs through provision of products that satisfy the consumers. This study is an assessment of the influence of smartphone attributes on student's buying decision in Lagos state tertiary institutions. The independent variables are Price, technology, design, application and image and the independent variable is student buying decision. The population of study was students in two selected tertiary institution in Lagos State. A total of 362 copies of questionnaire were administered to the students in this institutions, however, 327 questionnaires were retrieved from the respondent giving a response rate at 90.3 percent. Inferential statistics such as correlation and multiple regression analysis were used to analyze the data. The result showed that all product attributes considered in this study positively and significantly influence students buying decision of smartphone. Specifically, technology attribute has high impact on students buying decision of smartphone, followed by application and price attributes. The study concluded that technology, application and price are considered the most top three attributes that significantly influence students buying decision of smartphone. Based on the analyzed data and the tested hypothesis of the research work, the following recommendations are considered to be useful to smartphone companies, managers and practitioners in the field of marketing. The study recommends that firms should focus on improving their technology in other to bring about innovative features and application, and more importantly adopt variety of price strategies while not neglecting the image and design attributes, as these were regarded as secondary attributes in determining consumers' choice of smartphones.

\section{REFERENCES}

Aaker, D.A., Batra, R. \& Myers, J.G. (1992). Advertising management. $4^{\text {th }}$ ed. Prentice Hall, London.

Belch, G.E \& Belch, M.A. (2003). Advertising and promotion: $6^{\text {th }}$ ed. S.I. The McGraw Hill Companies

Das, D. (2012). An empirical study of factors influencing buying behavior of youth consumers towards mobile handsets: A case study in coastal districts of Odisha. Asian Journal of Research in Business Economics and Management, 2(4), 68 
Dodds, W. \& Monroe, K. B. (1985). The effect of brand choice information on subjective product evaluations, in Hirschman, E.C., \& Holbrook, M.R.

Dorsch, M.J., Grove, S.J. \& Darden, W.R. (2000). Consumer intensions to use a service category, Journal of Services Marketing. 14(20), 92-117

Dziwornu, R. K. (2013). Factors Affecting Mobile Phone Purchase in the Greater Accra Region of Ghana: A Binary Logic Model Approach. International Journal of Marketing Studies, 5 (6), 151-162

Fishbein, M.A. (1963) An Investigation of the Relationships between Beliefs about an Object and the Attitude Toward That Object, Journal of Human Relation, vol. 16 (3), pp. 233239.

Han, S. H., Kim, K. J., Yun, M. H., Hong, S. W., \& Kim, J. (2004). Identifying mobile phone design features critical to user satisfaction. Human Factors and Ergonomics in Manufacturing \& Service Industries, 14(1), 15-29

Idoko, E., Ireneus, N.C., Nkamnebe, A.D. \& Okoye, V.I. (2013). Effect of intrinsic and extrinsic product cues on consumers purchase intension: A study of alcoholic beverage consumer in a developing country metropolitan city, Journal of Arts, Science and Commerce, 4(3).

Jacoby, S \& Olson, J.C. (1985). Perceived quality, Lexington MA: Lexington books, 209-232.

Jobber, D. (2004) Principles and practice of marketing, $4^{\text {th }}$ ed. U.K. McGraw-Hill International Ltd.

Karen, L.L., Han, K.S. \& Benjamin, C.Y. (2013) Factors affecting Smartphone purchase decision among Malaysian generation, International Journal of Asian Social Science, 3 (12), 24262440
Karjaluoto, H., Karvonen, J., Kesti, M., Koivumaki, M., Pakola, J., Ristola, A. \& Salo, J. (2005). Factors affecting consumer choice of mobile phones: Two studies from Finland, Journal of Euromarketing, 14(3), 59-82.

Khan, S. \& Rohi, S. (2013). Investigating the factors affecting youth brand choice for mobile phones purchase - A study of Private Universities Students of Peshawar. Management and Marketing, 8(2), 369.

Kotler, P \& Armstrong, G. (2012) Principles of marketing, $14^{\text {th }}$ Ed. New Jersey, Pearson Education.

Kotler, P. \& Keller, K.L. (2012) Marketing management, $14^{\text {th }}$ Ed. New Jersey, Pearson Education.

Kotler, P., Armstrong, G., Saunders, J. \& Wong, V. (2002) Principles of marketing, $3^{\text {rd }}$ European ed. England, Pearson education Ltd.

Lancaster, K.J. (1966) A new approach to consumer theory, journal of political economy, 74, 132-157.

Lau, M.M., Lan, A.Y.C., \& Cheung, R. (2016). Examining the factors influencing purcgase intention of smartphone in Hong Kong, Contemporary management research, 12(2), 213-224.

Lay-yee, K., Kok-siew, Han, Yin-fah \& Benjamin (2013). Factors affecting smartphone purcahase decision among Malasian generation $\mathrm{Y}$, International Journal of Asian Social Science, 3(12), 2426-2440.

Ling, C., Hwang, W., \& Salvendy, G. (2006). Diversified users' satisfaction with advanced mobile phone features. Universal Access in the Information Society, 5(2), 239-249.

Lonial, S.C. \& Selimzaim, (2015) Investigation of product attributes and their effect on overall satisfaction. 
Malasi, J.M. (2012) Influence of Product Attributes on Mobile Phone Preference among University Students: A Case of Undergraduate Students, International Journal of Academic Research in Economics and Management Sciences, 1(6), 10-14

Mohan, A. (2014). Consumer behavior towards smartphone industry in indian market, Master of business administration thesis, Dublin business school.

Mojaye, E.M. (2015) Mobile phone usage among Nigerian University students and its impact on teaching and learning, Global Journal of Arts Humanities and Social Sciences, 3(1), 29-38.

Mokhlis, S., \& Yaakop, A. Y. (2012). Consumer Choice Criteria in Mobile Phone Selection: An Investigation of Malaysian University Students. International Review of Social Sciences \& Humanities, 2(2).

Oghojafor, B.A., Ladipo, P.K, \& Rahim, A.G (2012). The influence of product attributes on consumer purchase decision in the Nigerian food and beverage industry: a study of Lagos Metropolis, American Journal of Business and Management, 1 (4), 196201.

Park, T., Wiriady, D., Sarya, N. \& Putri, C. (2014). Factors impacting on university student's choice of mobile phone: Malaysian case, Proposal, Monarsh University.

Peter, J.P. \& Olsen, J.C. (1994). Understanding consumer behavior. $3^{\text {rd }}$. ed. Boston: Irwin.

Sabnam, S. (2016). Influencing factors on consumer buying behavior of smartphones: A Research on the buying behavior of young consumer in Kathmondu, Nepal, Bachelor Thesis, Business Administration, International Business School.
Sata, M. (2013) Factors affecting consumers buying behavior of mobile phone devices, Mediterranean Journal of Social Sciences, 4(12).103-112.

Seiler, W. J. \& Beall, M. L. (2005). Communication: Making connections. USA: Pearson education Inc.

Shaharudin,M.R,Hassan,A.A., Mansor,S.W., Elias,S.J., Harun,E.H \& Aziz,N.A (2010). The relationship between extrinsic attributes of product quality with brand loyalty on Malaysia national brand motorcycle/sector, Canadian social science, 6, (3), 165175.

Singh, J., \& Goyal, B. B. (2009). Mobile handset buying behavior of different age and gender groups. International Journal of Business and Management, 4 (5), 179.

Solomon, M.R., Bamoss, G.J., Askegaard, S.t. \& Hogg, M.k. (2013). Consumer behavior: A European perspective, 5th ed. Harlow, Pearson education limited.

Tan,W., Yeh, Y., Lin, Y. \& Kuo. C. (2015). How consumers assess product's features? : A case study of product features of Smartphone, recent researches in applied mathematics and economics.

Uys, W., Mia, A., Jansen, G.J., Van der schyff, H., Josias, M.A., Khusu, M., Gierdien, M., Leukes, N.A., Faltein, S., Gihwala, T., Theunissen, T., \& Samsonien, Y. (2012). Smartphone application usage amongst students at a South African university. International information Management Corporation.

Zhang, T., Rau, P.L., \& Zhou, J. (2015) Consumer perception of mobile phone attributes. 